\title{
The potential for implementation of liquid thermal insulation in organizational and technological solutions
}

\author{
Dmitry Topchy, Aleksey Yurgaytis, Alina Manakhova and Karina Mustafina \\ Moscow State University of Civil Engineering, Yaroslavskoe shosse, 26, Moscow, 129337, Russia
}

\begin{abstract}
Nowadays, the consumer is provided with an extensive selection of various thermal insulation materials. Particularly interesting is the possibility of using liquid insulation in the construction of new facilities, as well as overhaul and renovation programs. This article is devoted to the introduction of relatively new building material on the market - thermal paint (liquid insulation). It features the key characteristics of the product and provides a set of conclusions about its applicability and safety in comparison with other insulation materials according to the results of research and testing. The necessary steps for a massive project introduction of the material into the industry are given, taking into account the development of organizational and technological solutions, depending on the conditions of using this material.
\end{abstract}

\section{Introduction}

The ensuring of thermal performance of the buildings and structures is an integral part of the Energy Saving program in Russia. Comfort guarantee of the living conditions of people, monitoring energy consumption, compliance with environmental and fire safety are among the many conditions imposed on modern construction projects. In this regard, one of the most important issues is the one of development, implementation and monitoring new energy-efficient thermal insulation materials in accordance with the regulatory requirements of "SP 50.13330.2012 Thermal performance of the buildings. The updated edition of SNiP 23-02-2003" (rus).

Today, a wide range of insulation products on the market covers fibrous materials (based on glass and basalt fibers, mineral and slag wool), hard types of insulation, heatreflecting films, etc.

Depending on the method of heat transfer, thermal insulators can be divided into:

- Reflective type. This type of insulation reduces heat consumption due to the reduction of infrared radiation. The material consists of two layers: the main and the reflective one. The latter has a high coefficient of reflectivity (polished aluminum foil).

- Preventing type. By type of raw materials, they are divided into organic, inorganic and mixed. Preventing types of insulation are the main element of the finishing structures of the house due to their inherent low coefficient of thermal conductivity. During installation, preventive materials of the aggregate state are divided into liquid (penoizol, polyurethane foam), solid (foamed glass, polystyrene foam), soft (rockwoll), and bulk (expanded clay, 
slag). The choice of type depends on the insulated surface of the structure (often soft thermal insulation is used for vertical structures, solid and bulk - for horizontal structures).

Consider the main characteristics of insulation materials that subject to mandatory certification on the territory of the Russian Federation in accordance with the «Decree of the Government of the Russian Federation No. 982 dated December 1, 2009» (as amended on February 21, 2018) (see table 1) [1-5].

Table 1. Comparative analysis of thermal insulation materials

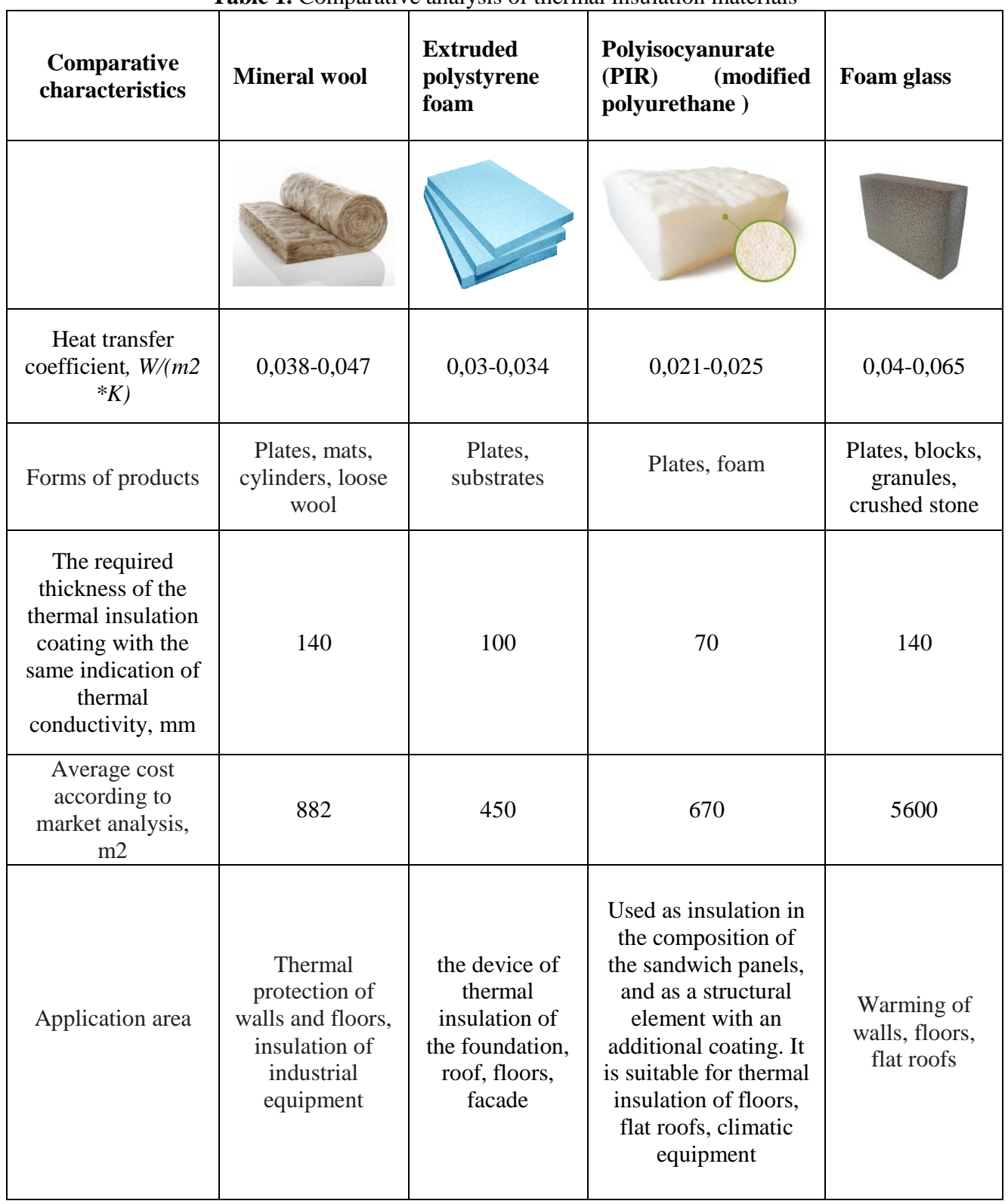

But the main criterion for the selection of thermal insulation is the coefficient of thermal conductivity. The minimum thickness of the heat-insulating material used directly depends on this coefficient. Since current trends in the development of the construction materials 
market are aimed at facilitating the construction of buildings due to the thickness of the structure and at providing significant savings in technological processes of construction and maintenance of the building it is worthwhile to single out an energy-efficient material that is relatively new to building practice, with a declared by low thermal conductivity coefficient and a small thickness of application - liquid thermal insulation (thermal paint).

\section{General information about liquid thermal insulations}

Thermal paint is a liquid composition consisting of:

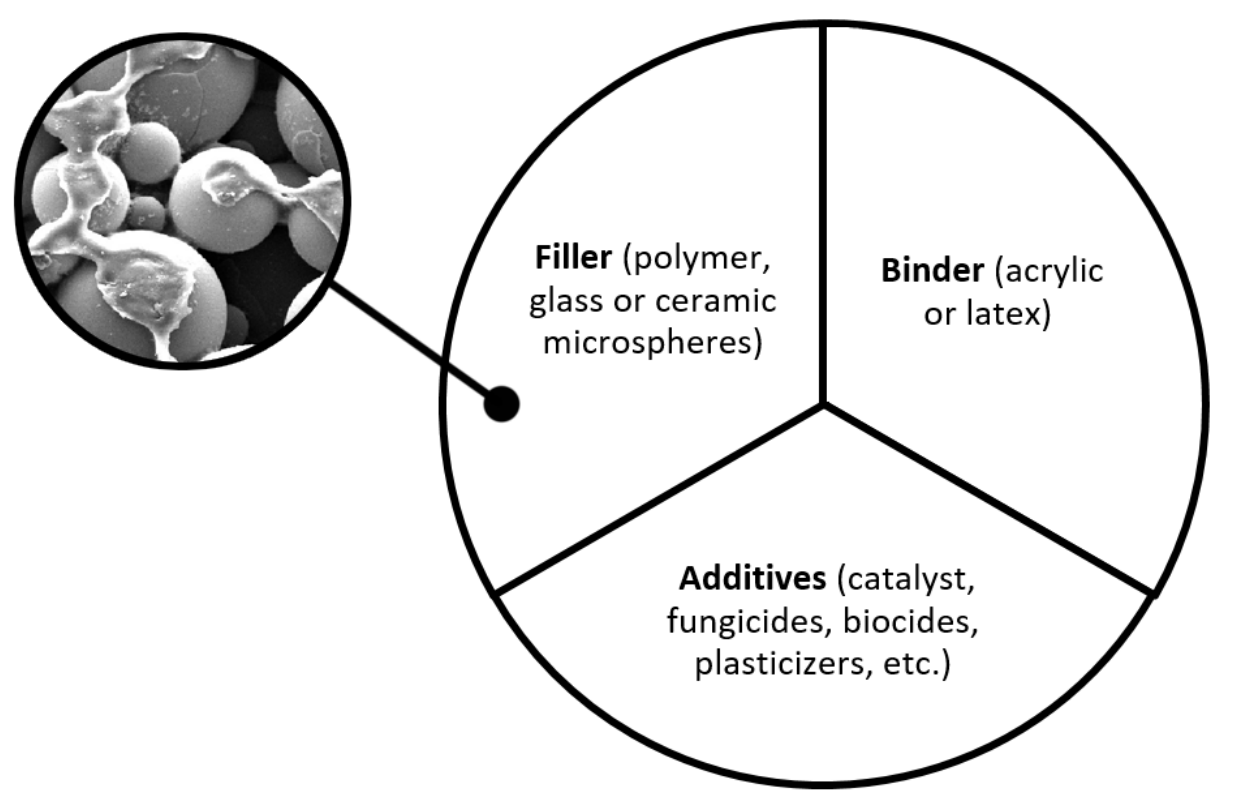

The production of liquid insulation is based on a standardized technology for introducing hollow microspheres and vacuum microspheres into the composition of the binder. When all components are mixed, clusters bonded to each other with a polymer form a structured suspension. As a result, the polymer base acquires thermal insulation properties. Despite the simplicity of the principle of production, this scheme requires a rather complex ratio of components. The correct balance of these elements allows to obtain high adhesive properties and durability of finished coatings. It is especially important to check the percentage content of the filler (80-85\%) in the liquid thermal insulation, which is the main element of the composition that prevents heat transfer through the construction. The filler microspheres possess properties of vacuum and have a thermal conductivity of $0.0012 \mathrm{~W} / \mathrm{mK}$, due to which the maximum insulation effect is achieved. This figure is often given by producers of thermal insulation paint as the coefficient of thermal conductivity. But it is worth clarifying that the total coefficient in the final product, according to the experiments, is 0,053 to $0,082 \mathrm{~W} / \mathrm{mK}$, that is significantly inferior in this indicator to such classic heaters as stone wool, foamed polystyrene, etc. (see table 1).

For a better acquaintance with the material, consider its other averages: 
Table 2.Averaged characteristics of liquid thermal insulation

\begin{tabular}{|l|l|}
\hline \multicolumn{1}{|c|}{ Characteristics } & \multicolumn{1}{c|}{ Value } \\
\hline Thermal conductivity & $0,053-0,082 \mathrm{~W} / \mathrm{mK}$ \\
\hline Moisture resistance & $\begin{array}{l}\text { It does not absorb moisture. Water absorption of the coating } \\
\text { within } 24 \text { hours } \leq 15 \%\end{array}$ \\
\hline Vapor permeability & Vapor permeability coefficient $\leq 0,02 \mathrm{mg}$ \\
\hline $\begin{array}{l}\text { Fire-resistance } \\
\text { Flammability } \\
\text { Smoke generation }\end{array}$ & $\begin{array}{l}\text { B2 } \mathrm{G} 1 \text { (Low degree) } \\
\text { D2 (Moderate) }\end{array}$ \\
\hline $\begin{array}{l}\text { Operational } \\
\text { temperature }\end{array}$ & $-50+200{ }^{\circ} \mathrm{C}$ \\
\hline Tensile strength & $8,7 \mathrm{~kg} / \mathrm{cm} 2$ \\
\hline $\begin{array}{l}\text { Middle density } \\
\text { Adhesion of coating on } \\
\text { the pulling power }\end{array}$ & $\begin{array}{l}\text { to steel }-0,6 \text { MPa } \\
\text { to the concrete surface }-1,0 \text { MPa }\end{array}$ \\
\hline $\begin{array}{l}\text { Time of the drying of } \\
\text { the single-layer coating }\end{array}$ & $8-24$ hours \\
\hline $\begin{array}{l}\text { Biological } \\
\text { sustainability }\end{array}$ & It hinders the development of microbial communities \\
\hline $\begin{array}{l}\text { Environmental } \\
\text { performance }\end{array}$ & $\begin{array}{l}\text { Environmentally safe, non-toxic. Ability to work with water- } \\
\text { based material in rooms without ventilation without using of } \\
\text { personal } \\
\text { protective equipment (PPE). On a varnish basis, with good } \\
\text { ventilation. }\end{array}$ \\
\hline $\begin{array}{l}\text { A labor cost according } \\
\text { to TSN-2001, } \\
\text { (per 100 m2 of } \\
\text { insulated surface) } \\
\text { congevity for the } \\
\text { surfaces }\end{array}$ & $\begin{array}{l}9,2 \text { employee hours } \\
\text { not less than } 7\end{array}$ \\
\hline
\end{tabular}

\section{Computational and experimental study of the effectiveness of the insulating paint}

To be able to make an objective assessment of the feasibility of using liquid insulation, tests were conducted. Consider the work of the paint as a barrier to prevent heat loss during concreting and heating of bored piles using casing in the conditions of the Far North.

Tasks set during the experiment:

1. Conducting a series of laboratory tests with the fixation of monitored values using profile equipment

2. Creating a model for testing, which has the most similar characteristics with the actual operating conditions

3. Results processing 
4. Formation of the conclusion about the feasibility of using thermal paints on the basis of the tests performed.1.

Type of work - installation of a pile substructure from bored piles using casing on permafrost soils.

Environment parameters:

- Temperatures of the heated concrete mix is $15^{\circ} \mathrm{C}$

- Average ground temperature around the casing walls is $0{ }^{\circ} \mathrm{C}$

- Casing pipe parameters:

- $\quad$ pipe material is steel;

- outer diameter is $920 \mathrm{~mm}$;

- wall thickness is $12 \mathrm{~mm}$;

Based on the features of real conditions, choose a model for testing:

The test samples are two steel pipes with a diameter of $210 \mathrm{~mm}$ and a wall thickness of $5 \mathrm{~mm}$. In order to bring the conditions closer to those in which further the use of liquid thermal insulation is implied, during the experiment we use the climate chamber that maintains the temperature regime at $0{ }^{\circ} \mathrm{C}$. To simulate thermal radiation arising from the hydration of concrete, a heat emitter is used, which is connected to a rheostat to control the intensity of thermal radiation. Consequently, we obtain a temperature differential in the air inside and outside the pipe $-15^{\circ} \mathrm{C}$, that corresponds to real conditions.

The first sample is processed according to the recommendations for applying liquid thermal insulation specified by the manufacturer. Apply the paint in one layer on the previously prepared surface (dry, clean, durable) with a brush or airless sprayer. Before use, thoroughly mix the product, adding water to a volume of $10 \%$ of the nominal volume of use of materials.

The second sample is tested without finishing. Place the samples in the climatic chamber, having previously installed one heat radiator in each pipe in order to control the temperature rise inside the pipe. Using a small piece of thermal insulation boards, close the end side of the pipe to avoid the appearance of cold joints. Then within 25 minutes we test samples. After, using a thermal imaging with an interval of 1 minute, we record 20 temperature readings on the outer surface of the casing. Thus, 45 minutes after the start of the test, the last survey is completed.

After the end of the test, the sources of thermal radiation are turned off and samples are taken from the climate chambers.

We carry out the processing of test results. Thus, we determine the temperature difference between the outer surfaces of pipes on 2 samples: with the use of thermal paint and without its use.

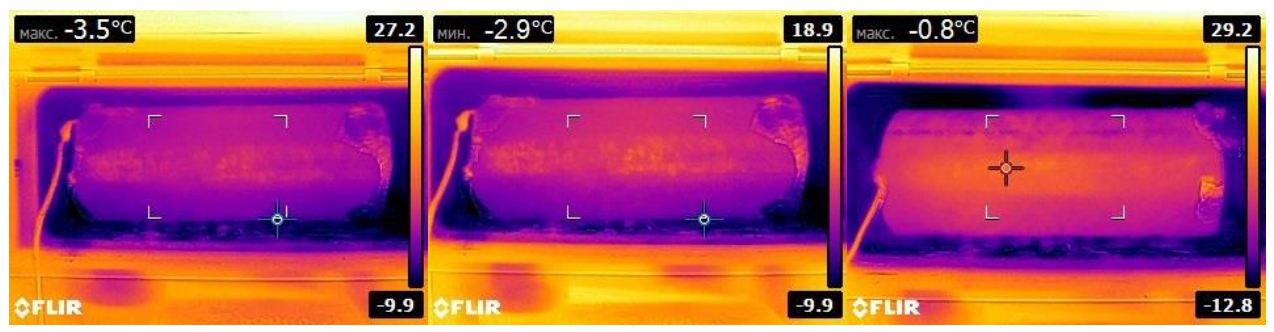

Fig. 1. The photographing data of the pipe specimen without liquid insulation by the thermal imager. 
Within 20 minutes, the temperature on the outer surface of the pipe, which is not treated with thermal paint, is constantly growing. Below is a graph of the sample temperature during the test.

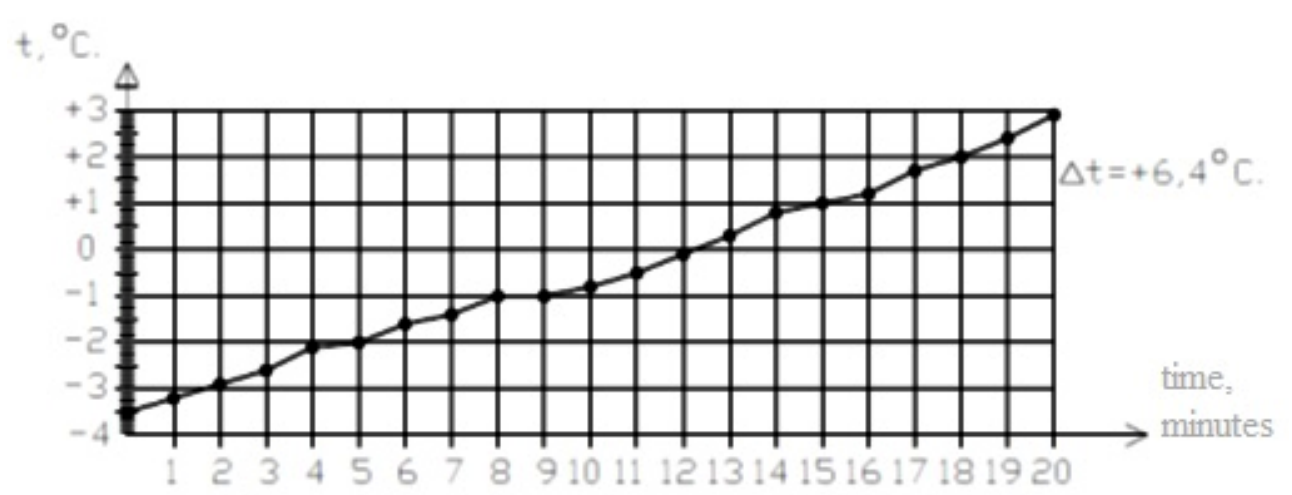

Fig. 2. The graph of the temperature change of the sample pipe without thermal insulation paint

The graph shows how owing to the internal heating of the pipe, its surface temperature changed by more than 6 degrees.

The schedule shows how, the temperature of its surface has changed due to the internal heating of the pipe by more than 6 degrees. Below contains the outcome of a thermal imaging survey of a sample covered with a thermal paint. If you compare the results of surveys, you can see the difference in temperature change. It can also be seen that there is a pronounced heated spot in the uncoated sample.

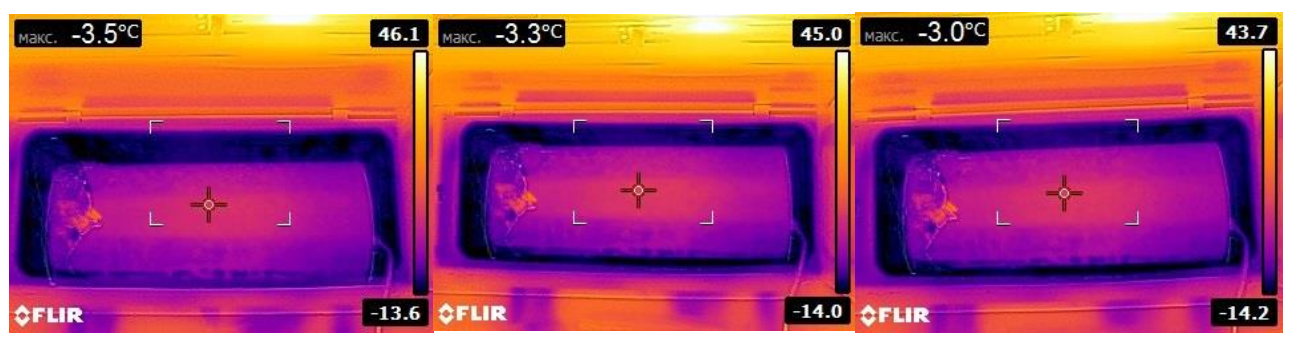

Fig. 3. The photographing data of the pipe specimen with liquid insulation by the thermal imager

Similarly, we present a graph of the temperature change of the pipe in the second case.

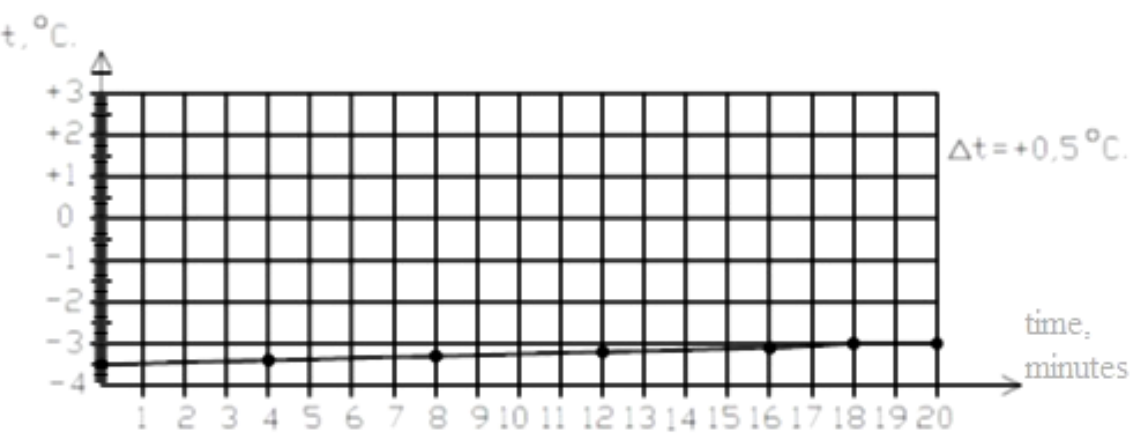

Fig. 4. The graph of the temperature change of the sample pipe with liquid insulation. 


\section{Assessment according to the current status of the test}

From a technological perspective, it is justified to use liquid insulation when setting up bored piles in the Far North, because the thermal insulation paint has good adhesion to steel and is easily applied to the surface and does not require additional measures to care for the surface that has been treated. In addition, the experiment showed that liquid insulation prevented heat losses in the sample.

\section{Modeling of organizational and technological solutions for the application of liquid thermal insulation}

Although thermal insulation paint is not suitable as a universal material and cannot claim to primacy among modern heaters in terms of physical properties, in some cases the use of liquid insulation is economically and technologically justified [6-9]. Often it is used in places where it is impossible or difficult to do with traditional insulating materials. Consider the possible uses of thermal paint:

Table 3. Scope of thermal insulation paint

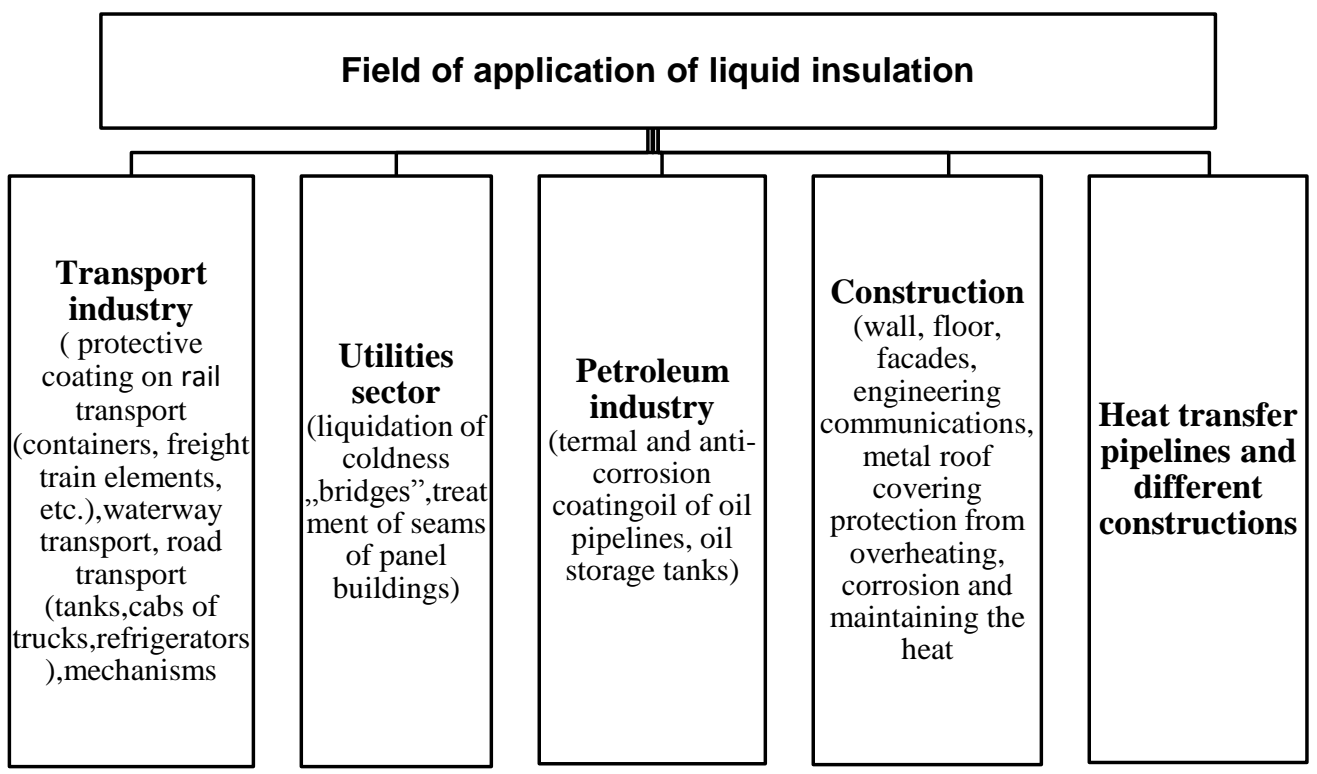

At the moment, manufacturers only display general provisions for the use of thermal paints in their instructions. Due to the fact that the liquid thermal insulation has a fairly extensive scope of use, often the data provided is not sufficient for the consumer. Therefore, for the mass introduction of the product to the market, there is a need to create typical flow chart which would take into account all the nuances of using thermal paint. The development of such typical flow chart will allow to correctly apply the liquid thermal insulation taking into account the peculiarities of the environment and the insulated surfaces.

An indicative list of technological operations:

1. Quality control 


\subsection{Surface preparation}

According to the manufacturer, liquid insulation has a high adhesion, which makes it possible to use the product on surfaces of various properties.

Table 4. Scope of application liquid insulation by materials

\begin{tabular}{|l|c|}
\hline \multirow{4}{*}{$\begin{array}{l}\text { Scope of application liquid } \\
\text { insulation by materials }\end{array}$} & metal \\
\cline { 2 - 2 } & wooden \\
\cline { 2 - 2 } & concrete \\
\cline { 2 - 2 } & plastic \\
\cline { 2 - 2 } & brick \\
\hline
\end{tabular}

When developing a typical flow chart to preserve the adhesive properties of the product, it is necessary to identify the technology of products surface preparation under painting (depending on the type and condition of the work surface).

\subsection{Preparation of thermal insulation}

It is important to take into account changes in the characteristics of the liquid insulation and features of its work, depending on the following conditions:

- temperature of the insulated surface

- ambient temperature

- radiation

- precipitation

- humidity, etc.

\section{Application Instructions}

It is necessary to describe in detail with what device and tools (paint brush, paint roller, spray gun, etc.) it is possible to apply the product. And also indicate the recommendations for their use, taking into account the area of the treated surface.

\section{Safety}

To organize safe working conditions when working with liquid thermal insulation, it is important to focus on studies confirming the environmental friendliness of thermal paint. Thus, it is necessary to conduct laboratory tests and check the product for the release of hazardous substances, comparing the obtained values with the maximum permissible according to the "Uniform Sanitary Epidemiological and Hygienic Requirements for the Goods Subject to Sanitary and Epidemiological Supervision (Control) (with changes for May 10 2018)

Table 5. Allowable limit of migration of chemical into the environment

\begin{tabular}{|c|c|}
\hline A chemical substance & Allowable limit of migration of chemical in to air, $\mathbf{~ m g} / \mathbf{m} \mathbf{3}$ \\
\hline Styrene & 0,002 \\
\hline Ammonia & 0,04 \\
\hline Phenol & 0,003 \\
\hline
\end{tabular}




\begin{tabular}{|c|c|}
\hline Phenol & 0,01 \\
\hline Sulphur dioxide & 0,05 \\
\hline
\end{tabular}

4. Maintenance of the coating

In developing typical flow chart should bring recommendations on updating of cover and the surface maintenance during operation

These stages can lead to the widespread introduction of liquid insulation in modern construction production:

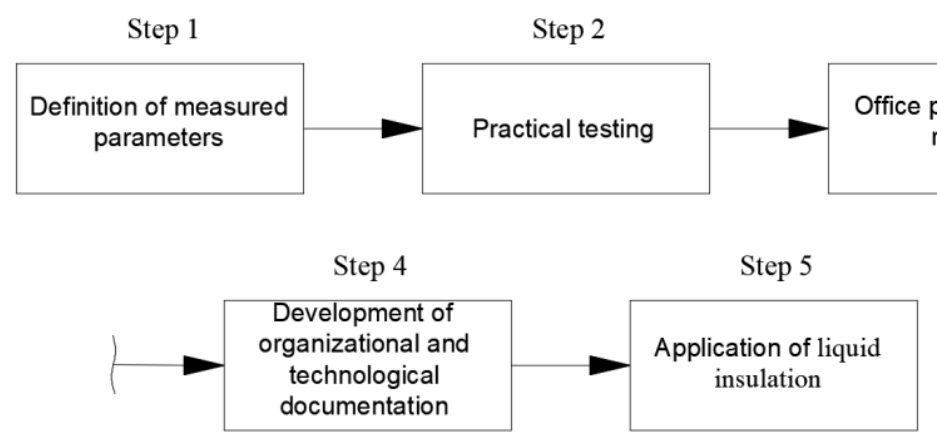

\section{Conclusion}

Based on the analysis we can draw the following conclusions:

1. It is advisable to use the paint in the implementation of building and overhaul of civilian buildings (including underground parts) due to its verified thermal insulation properties, low labor costs.

2. For the mass introduction of liquid insulation to the market, it is necessary to conduct research in the following areas:

2.1. Conduct tests that prove the safety and environmental friendliness of the product

2.2. Develop standard flow charts taking into account the diversity of applications of liquid thermal insulation.

\section{References}

1. Yu.L. Bobrov, E.G. Ovcharenko, B.M. Shoikhet, E. Yu. Petuknova, Thermal isolating materials and constructions 267 (UNFRA-M, 2003)

2. V.V. Plotnikov, V.M. Bogatovsky, Modern technologies to improve the thermal protection of buildings 134 (BGITA, 2010)

3. L.I. Chumadova, M.Yu. Skorikov, T.G. Stepanian, M.V. Morozov, D.M.Vestnikov Thermal characteristics of liquid ceramic insulation material based on aluminum silicate and sodium borosilicate microspheres (Internet journal Modern Research and Innovation, 2016)

4. Uniform Sanitary Epidemiological and Hygienic Requirements for the Goods Subject to Sanitary and Epidemiological Supervision (Control) (with changes for May 10, 2018)

5. Decree of the Government of the Russian Federation No. 982 dated December 1, 2009 (as amended on February 21, 2018)

6. P. Oleinik, A. Yurgaytis, MATEC Web of Conferences, 117, 00130, (2017), https://doi.org/10.1051/matecconf/201711700130 
7. D. Topchiy, A. Shatrova, A. Yurgaytis, MATEC Web of Conferences, 193, 05032, (2018), https://doi.org/10.1051/matecconf/201819305032

8. P. Oleinik, A. Yurgaytis, MATEC Web of Conferences, 193, 05010, (2018), https://doi.org/10.1051/matecconf/201819305010

9. M. Rogalska, W. Bozejko, Z. Hejducki, Automation in Construction, 18, 24-31, (2008), doi:10.1016/j.autcon.2008.04.002 